\title{
Percutaneous mitral balloon valvuloplasty in patients with previous surgical mitral commissurotomy
}

\author{
Mir Jamal Uddin'1, Fazlur Rahman², Mohammad Salman², Khondker Shaheed Hussain¹, \\ M. Shahinur Rahman ${ }^{3}$, Md. Amir Hossain ${ }^{4}$, Khairul Anam², Md. Mukhlesur Rahman², Md. Khurshed Ahmed ${ }^{2}$ \\ ${ }^{1}$ National Institute of Cardiovascular Diseases and Hospital Dhaka \\ ${ }^{2}$ Department of Cardiology, UCC, Bangabandhu Sheikh Mujib Medical University, Dhaka \\ ${ }^{3}$ Department of Cardiology, Sir Salimullah Medical College \& Mitford Hospital, Dhaka \\ ${ }^{4}$ Department of Cardiology, Bangladesh Medical College Dhaka
}

Address for correspondence

Dr. Fazlur Rahman, Associate Professor, Department of Cardiology, UCC

Bangabandhu Sheikh Mujib Medical University, Dhaka

E-mail : frahman.card@yahoo.com

\begin{abstract}
This prospective observational study was done in National Institute of Cardiovascular Diseases and hospital Dhaka, during the period April 2002 toJuly 2008. In this study the immediate results of balloon mitral valvuloplasty with mitral restenosis patients with previous surgical mitral commissurotomy was evaluated. We have done 50 cases of percutaneous balloon mitral valvuloplasty in patients who had the history of previous surgical commissurotomy. Out of these 50 patients 8 patients were male and 42 patients were female. The age range was $25-55$ years with duration of surgical commissurotomy (SC) of 2-18 years past. The result of balloon mitral valvuloplasty (BMV) was successful in 48 cases and failed in 2 cases due to huge left atrium, balloon did not negotiate from LA to LV. Mitral valve area (MVA) before the procedure was $0.5-0.9 \mathrm{sq} \mathrm{cm}$ with mean $0.7 \pm 2 \mathrm{sq} \mathrm{cm}$. Following procedure the MVA was $1.6-2.04 \mathrm{~cm}^{2}$ with a mean of $1.8 \pm 0.2 \mathrm{~cm} 2$. Gradient across mitral valve (MV) before and after the procedure was $20-44 \mathrm{~mm} \mathrm{Hg}$ with a mean of $32 \pm-12 \mathrm{~mm} \mathrm{Hg}$ and $8-12 \mathrm{mmHg}$ with a mean of $10 \pm 2 \mathrm{~mm}$ $\mathrm{Hg}$. MVA $\geq 1.8 \mathrm{~cm}^{2}$ was achieved in 41 cases $\& 1.8-1.6 \mathrm{~cm}^{2}$ in 7 cases. Mitral regurgitation $\geq 1$ grade occurred in 8 cases. So we conclude that BMV in patients with mitral restenosis following SC can be performed successfully with low risk of major cardiac complications.
\end{abstract}

Key wards: Surgical commissurotomy (SC), balloon mitral valvuloplasty (BMV)

\section{Introduction}

The prevalence of mitral stenosis in developed countries, is $0.5 / 100,000$. Its prevalence in developing countries is at least 10 times higher than in developed countries. ${ }^{1}$ Closed mitral commissurotomy is still considered as a treatment of choice in developing countries in particular for economic reason. It is estimated that about $10-30 \%$ of patients developed restenosis 5-10 years after an initial successful surgical commissurotomy. ${ }^{2}$ The efficacy of Percutaneous balloon mitral valvuloplasty (BMV) in patients with unoperated mitral stenosis has been well documented though there exists less clear-cut data on its effectiveness in patients with mitral restenosis following closed mitral commissurotomy (CMC). Therefore, in this study, we analyzed our results obtained with balloon mitral valvuloplasty in patients with mitral restenosis after previous surgical commissurotomy.

\section{Methods}

This study was done in National Institute of Cardiovascular Diseases (NICVD), Dhaka, Bangladesh. We performed 50 cases of BMV in patients who had the history of previous surgical commissurotomy. Among 50 patients undergoing BMV who received the procedure for symptomatic mitral restenosis after the duration of 2-18 years past the CMC.
There were 42 female and 8 male with age range 25 to 55 years. Echocardiographic score of the mitral apparatus, baseline mitral valve area were determined by echocardiography Presence of mitral regurgitation as determined by Color Doppler echo.

Table I: Demonstrable baseline clinical characteristics of study subjects $(\mathrm{N}=\mathbf{5 0})$

\begin{tabular}{|c|c|}
\hline Variables & No, of patients \\
\hline Age (Years) & $40 \pm 15$ \\
\hline Female: Male & $42: 8$ \\
\hline \multicolumn{2}{|c|}{ NYHA* $^{*}$} \\
\hline Class II & 13 \\
\hline Class III & 35 \\
\hline Class IV & 02 \\
\hline Atrial Fibrillation & 30 \\
\hline \multicolumn{2}{|c|}{ Mitral regurgitation } \\
\hline Grade 0 & 24 \\
\hline Grade 1 & 16 \\
\hline Grade 2 & 10 \\
\hline \multicolumn{2}{|c|}{ Echo score (Wilkins) } \\
\hline 8 & 14 \\
\hline 811 & 36 \\
\hline
\end{tabular}

*NYHA- New York Heart Association 


\section{Balloon mitral valvuloplasty technique}

Balloon mitral valvuloplasty was performed using an appropriate sized Inoue balloon catheter determined from the height of the patients and the stepwise dilatation technique. 3-4 The reference balloon size (RBS) in mm was determined from the height of the patient using the formula $\mathrm{RBS}=$ $\mathrm{H} / 10+10$ in $\mathrm{mm}$ where $\mathrm{H}$ is the patients height in $\mathrm{cm}$ e.g. if the height is $160 \mathrm{~cm}$ then the RBS will be $160 / 10+10=$ $16+10=26 \mathrm{~mm} \cdot{ }^{3-4}$ Balloon mitral valvuloplasty was terminated once a satisfactory hemodynamic result defined as a decrease of at least one half the initial transmitral gradients with no further reduction despite two or three more dilatations using larger balloon sizes of 0.5-1.0 mm increments was obtained (Fig:1 \& 2).

\section{Echocardiography}

All patients underwent 2D-E, M mode and Colour Doppler echocardiographic examination before and 2-4 weeks after balloon mitral valvuloplasty. Transesophageal echocardiography was performed 1-2 days prior to balloon mitral valvuloplasty to those patients having the history of previous left atrial thrombus or haziness found in left atrial appendage by transthoracic echocardiography. In this study mitral valve area $\left(\mathrm{cm}^{2}\right)$ were determined by planimetry and Doppler Pressure half time (PHT). Mitral valve area and subvalvular morphology was graded according to the Wilkins scoring system which assigns higher scores to values with more severe disease. ${ }^{5}$

Table II: Depicts hemodynamic changes and mitral valve area before and after the procedure $(n=50)$

\begin{tabular}{|c|c|}
\hline \multicolumn{2}{|c|}{ Transmitral peak pressure gradient (mmHg) } \\
\hline Before the procedure & $30 \pm 12$ \\
\hline After the procedure & $10 \pm 5$ \\
\hline Anglegraphic Mean left atrial pressure (mamHg) \\
\hline Before the procodure & $40 \pm 15$ \\
\hline After the procodure & $15 \pm 5$ \\
\hline \multicolumn{2}{|c|}{ Mlitral valve area (cm²) } \\
\hline Before the procedure & $0.7 \pm 0.2$ \\
\hline After the procedure & $1.7 \pm 0.5$ \\
\hline Optimul Commissurotomy & 41 case (82\%) \\
\hline
\end{tabular}

Table III: Showing complications arise after procedure $(\mathrm{N}=\mathbf{5 0})$

\begin{tabular}{|c|c|}
\hline Variable & Numbers \\
\hline Mitral regurgitation $\geq 1$ grade & 8 \\
\hline Froe wall puncture & 0 \\
\hline Acute LvF & 0 \\
\hline Systemic thrombo-embolism & 0 \\
\hline Puncture site hematoma & 1 \\
\hline Arterio-vebous fistula & 0 \\
\hline Failed procedure & 2 \\
\hline
\end{tabular}

\section{Definition}

Optimal commissurotomy - A valve area improvement of $\geq$ $50 \%$ or a final valve are $\geq 1.5 \mathrm{~cm} 2$, without resulted $\geq$ grade $3+$ angiographic mitral regurgitation.

\section{Results}

All procedures were completed without any major complications. In particular there were no cardiac perforation, no systemic embolism, need for emergent mitral valve surgery or death. The result of balloon mitral valvuloplasty (BMV) was successful in 48 cases and failed in 2 cases due to huge left atrium, balloon did not negotiate from LA to LV. Mitral valve area (MVA) before the procedure was 0.5-0.9 sq $\mathrm{cm}$ with mean $0.7 \pm 0.2 \mathrm{sq} \mathrm{cm}$. Following procedure the MVA was $1.6-2.04 \mathrm{sq} \mathrm{cm}$ with a mean of $1.7 \pm 0.5 \mathrm{sq} \mathrm{cm}$. Peak gradient across mitral valve (MV) before and after the procedure was 20-44 mm Hg with a mean of $30 \pm 12 \mathrm{~mm} \mathrm{Hg}$ and 8 -12 with a mean of $10 \pm 5 \mathrm{~mm} \mathrm{Hg}$. Adequate MVA $\geq 1.8 \mathrm{sq}$ $\mathrm{cm}$ was achieved in 41 cases. MVA 1.8-1.6 achieved in 7 cases. Mitral regurgitation $\geq 1$ grade than previous occurred in 8 cases. The pre and post procedural mean angiographic left atrial pressure was $40 \pm 15 \mathrm{mmHg}$ and $15 \pm 5 \mathrm{mmHg}$ respectively. The hemodynamic and echo results are depicted in table II. Optimal commissurotomy was done in $82 \%$ of patients. An increase in mitral regurgitation $\geq 1$ grade than previous occurred in 8 cases.

\section{Discussion}

This series further confirms the safety and immediate efficacy of BMV for restenosis after surgical commissurotomy, with $82 \%$ showing good immediate results. ${ }^{6-12}$

The composite end point of good immediate results used in this study associates a mitral valve area $1.5 \mathrm{~cm} 2$ and no regurgitation $>2 / 4$, such conditions generally providing normal hemodynamic. ${ }^{13-14}$ Patients who have a history of prior 
commissurotomy have more severe impairment of valve anatomy. Our findings are consistent with the work of Feldman et al. ${ }^{15}$ who showed that the impairment of valve anatomy was not a predictor of poor results of BMV. Valve calcification and the duration between surgery and BMV have been identified as predictors in other series ${ }^{6-8}$, but not in ours. It should be noted that valve calcification, when present, was generally mild or moderate in the patients of this series. There was no procedural related mortality and no cardiac perforation, stroke or emergency mitral valve surgery in the study.

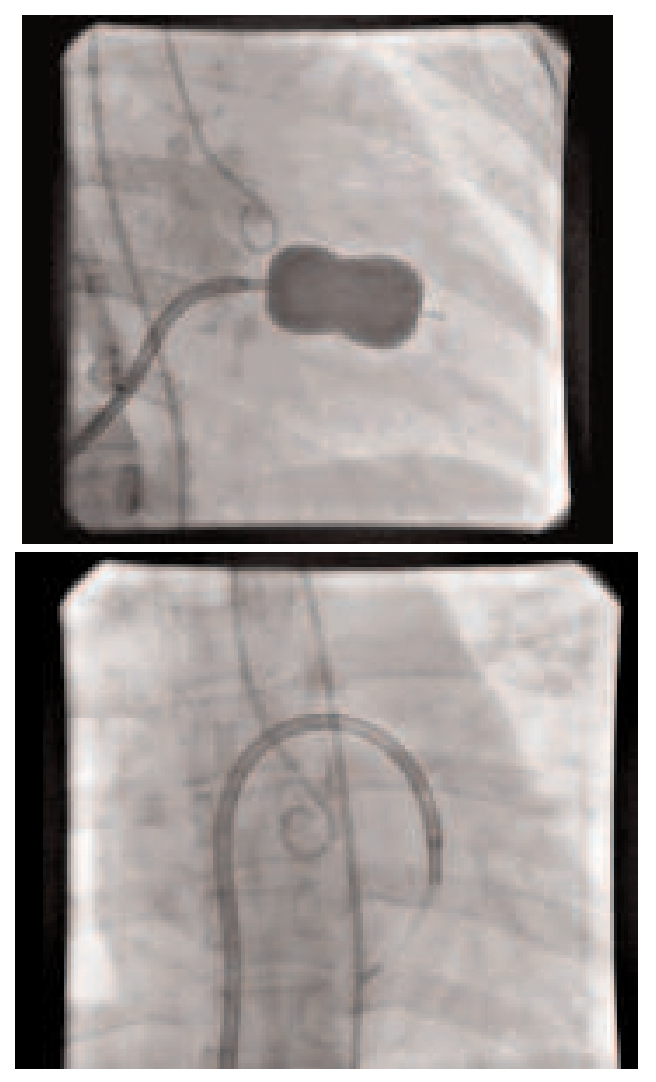

Only limited data exist on the short and midterm results of balloon mitral valvuloplasty in patients with mitral restenosis after previous surgical commissurotomy. ${ }^{16-19}$ The results of balloon mitral valvuloplasty in such a setting have been mixed. Davidson et. al. ${ }^{16}$ noted that balloon mitral valvuloplasty in these patients was associated with a significant smaller gain in mitral valve area and less sustained clinical benefits compared with those without prior mitral surgery. In contrast, our findings concurred with several other past studies $^{6-8}$ in that balloon mitral valvuloplasty yielded similar immediate improvement in the valve area and an identical risk of resultant mitral regurgitation. More recent data in a study from Boston ${ }^{10}$ revealed that although the immediate and midterm results in patients with mitral restenosis after previous surgical commissurotomy were generally inferior to those without past mitral surgery, these differences were no longer observed when patients with favorable overall mitral echo score $(\leq 8)$ were compared. However, the present study differs from some of these studies ${ }^{17-19}$ with respect to the incidence of technical failures, resultant severe mitral regurgitation and morbidity. Serra et.al. ${ }^{19}$ observed technical failure and major cardiac related complications in $11 \%$ of patients in their study. Medina et. al. ${ }^{17}$ in turn, noted resultant severe mitral regurgitation in $9.5 \%$ of patients and cited a $4.7 \%$ mortality rate. In contrast, there was no technical failure, severe mitral regurgitation or death in our patients with previous surgical commissurotomy. Possible explanations for these major discrepancies include the use of the Inoue balloon in the present study as opposed to the double balloon technique used in all the above mentioned studies and patient selection. This study demonstrates that balloon mitral valvuloplasty is safe in patients with mitral restenosis following prior surgical commissurotomy.

In conclusion it can be said that balloon mitral valvuloplasty in patients with mitral restenosis following surgical commissurotomy can be performed successfully with low risk of major cardiac complications. For these reasons balloon mitral valvuloplasty should be considered a logical first line of following surgical commissurotomy treatment strategy for selected patients of mitral restenosis.

\section{References}

1. Enio E, Guerios, Ronaldo B, et al. Mitral stenosis and percutaneous mitral valvuloplasty (Part 1). The journal of invasive cardiology. 2005; 17:382-86.

2. John S, Perianayagam WJ, Abraham KA, et al. Restenosis of mitral valve: Surgical consideration and result of operation. Ann. Thorac Surg. 1978; 25: 316-21.

3. Lau KW, Hung JS. A simple balloon sizing method in Inoue balloon Percutaneous trans venous mitral commissurotomy. Catheter cardiovasc Diagn 1994; 33:120-29.

4. Hung js, Law KW. Pitfalls and tips in Inoue balloon mitral commissurotomy. Catheter cardiovasc Diag 1996; 37: 188-99.

5. Wilkins GT, Weyman AE, Abascal VM, Block PC, Palcios I. Percutaneous balloon dilatation of the mitral valve: An analysis of echocardiographic variables related to outcome and the mechanism of dilatation. Br Heart J 1988; 60: 299-08. 
6. Medina A, Suarez De Lezo J, et al. Balloon valvuloplasty for mitral restenosis after previous surgery: a comparative study. Am Heart J. 1990; 120:568-71.

7. NHLBI balloon valvuloplasty registry participantsDavidson CJ, Bashore TM, Mickel M, Davis K. Balloon mitral commissurotomy after previous surgical commissurotomy. Circulation. 1992;86:91-99.

8. Serra A, Bonan R, Lefevre T, et al. Balloon mitral commissurotomy for mitral restenosis after surgical commissurotomy. Am J Cardiol 1993;71:1311-15

9. Sharma S, Loya YS, Desai DM, Pinto RJ. Balloon valvotomy for mitral restenosis after open or closed surgical commissurotomy. Int J Cardiol. 1993;39:103-08

10. Jang IK, Block PC, Newell JB, et al. Percutaneous mitral balloon valvotomy for recurrent mitral stenosis after surgical commissurotomy. Am J Cardiol. 995;75:601-05

11. Lau KW, Ding ZP, Gao W, et al. Percutaneous balloon mitral valvuloplasty in patients with mitral restenosis after previous surgical commissurotomy: a matched comparative study. Eur Heart J. 1996;17:1367-72.

12. Gupta S, Vora A, Lokhandwalla Y, et al. Percutaneous balloon mitral valvotomy in mitral restenosis. Eur Heart $J$. 1996;17:1560-1564
13. Iung $\mathrm{B}$, Cormier $\mathrm{B}$, Ducimetière $\mathrm{P}$, et al. Immediate results of percutaneous mitral commissurotomy: a predictive model on a series of 1,514 patients. Circulation. 1996;94:2124-30

14. Vahanian A, Michel PL, Cormier B, et al. Results of percutaneous mitral commissurotomy in 200 patients. Am J Cardiol.1989;63:847-52.

15. Feldman T, Carroll JD, Isner JM, et al. Effect of valve deformity on results and mitral regurgitation after Inoue balloon commissurotomy. Circulation. 1992;85:180-87

16. Rediker DE, Block PC, Abascal VM, Palacios IF. Mitral balloon valvuloplasty for mitral restenosis after surgical commissurotomy. J Am Coll Cardiol 1988; 11: 252- 56.

17. Medina A, Lezo JSD, Hernandez E et al. Balloon valvuloplasty for mitral restenosis after previous surgery; A comparative study. Am Heart J 1990; 120: 568- 71.

18. Davidson CJ, Bashore TM, Michel M, Davis K. Balloon mitral commissurotomy after previous surgical commissurotomy. Circulation 1992; 86: 91-99.

19. Serra A, Bonan R, Lefavre T et al. Balloon mitral commissurotomy for mitral restenosis after surgical commissurotomy. Am J Cardiol 1993; 71: 1311-15. 